\title{
Fever, anemia, and splenomegaly: A rare presentation of splenic angiosarcoma
}

\author{
Mridula Shukla, \\ Somprakash Basu ${ }^{1}$, \\ Vijay K. Shukla', \\ Mohan Kumar
}

Departments of Pathology, and ${ }^{1}$ Surgery, Institute of Medical Sciences, Banaras Hindu University, Varanasi, Uttar Pradesh, India

\section{Address for correspondence:}

Dr. Mridula Shukla,

Department of Pathology, Institute

of Medical Sciences, Banaras Hindu

University, Varanasi - 221 005,

Uttar Pradesh, India.

E-mail: drmridulashukla@gmail.com

\section{A B S T R A C T}

Splenic angiosarcoma is a rare neoplasm that often remains asymptomatic till the onset of massive intra abdominal bleeding that require emergency splenectomy. We report here a case of 60 year old male who presented with on and off fever and a splenomegaly was found on clinical examination suggesting a lymphoproliferative disorder. A contrast enhanced computerized tomography suggested splenic trauma with intracapsular bleed. A splenectomy was carried out that revealed splenic angiosarcoma. Splenomegaly and fever is a very rare presentation of angiosarcoma. Though rare it should be kept in mind when investigating pyrexia of unknown origin.

Key words: Angiosarcoma, fever, splenomegaly

\section{INTRODUCTION}

Angiosarcoma is a rare malignant neoplasm of endothelial cells, which represents less than $2 \%$ of all soft tissue sarcomas. Despite primary angiosarcoma of spleen being extremely rare, it is the most common primary nonlymphoid malignant lesion of spleen. Till date only 200 cases have been reported. ${ }^{[1]}$ Here we report a case of primary angiosarcoma of spleen presenting as on and off fever and anemia.

\section{CASE REPORT}

A 60-year-old male presented with complaints of on and off fever and lump in left upper abdomen of 1 month duration. Physical examination revealed pallor. Abdomen was soft, with no venous engorgement. There was a $10 \times 7 \mathrm{~cm}$ lump; $5 \mathrm{~cm}$ below left costal margin in midclavicular line. The lump was nontender with smooth surface and sharp margins. Bowel sounds were present. Laboratory evaluation showed anemia and leukocytosis; electrolyte and liver function tests were with in normal limits.

\begin{tabular}{|l|l|}
\hline \multicolumn{2}{|c|}{ Access this article online } \\
\hline Quick Response Code: & Website: \\
\hline & Www.jmpo.org \\
\hline & \\
\hline
\end{tabular}

General blood picture was suggestive of hemolytic anemia with spherocytes, target cells, and Howell-Jolly bodies. Chest X-ray, X-ray abdomen, and echocardiogram were unremarkable. Upper gastrointestinal endoscopy showed antral gastritis, suggesting segmental portal hypertension. Abdominal sonography and computed tomography (CT) showed splenomegaly with heterogeneous enlargement, subcapsular hematoma with multiple ill-defined nodules in the splenic parenchyma with minimal ascites, and left pleural effusion [Figure 1].
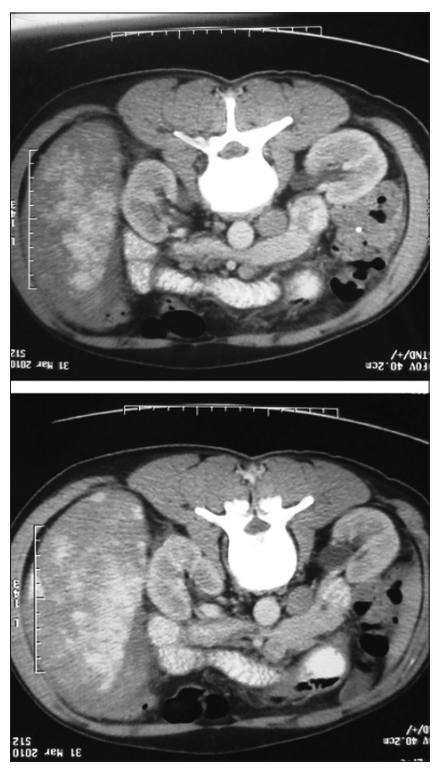

Figure 1: Computed tomography scan showing splenic enlargement with subcapsular hematoma 
Suspecting a splenic trauma in a congested enlarged spleen, a laparotomy with splenectomy was performed. On gross examination, spleen was enlarged in size with cut surface showing a circumscribed grey white area with diffuse hemorrhagic areas and multiple ill-defined nodules [Figure 2]. Microscopic examination showed the replacement of whole of the spleen by a vascular neoplasm composed of anastomosing vascular channels lined by atypical endothelial cells. Tumor was composed of solid areas and papillary fronds. These papillary fronds were lined by pleomorphic endothelial cells with pleomorphic hyperchromatic nuclei showing mitotic figures [Figures 3 and 4]. Areas of necrosis were also noted. The staining for CD31 was performed, which showed diffuse membranous positivity [Figure 5]. Based on these findings the diagnosis of angiosarcoma was made.

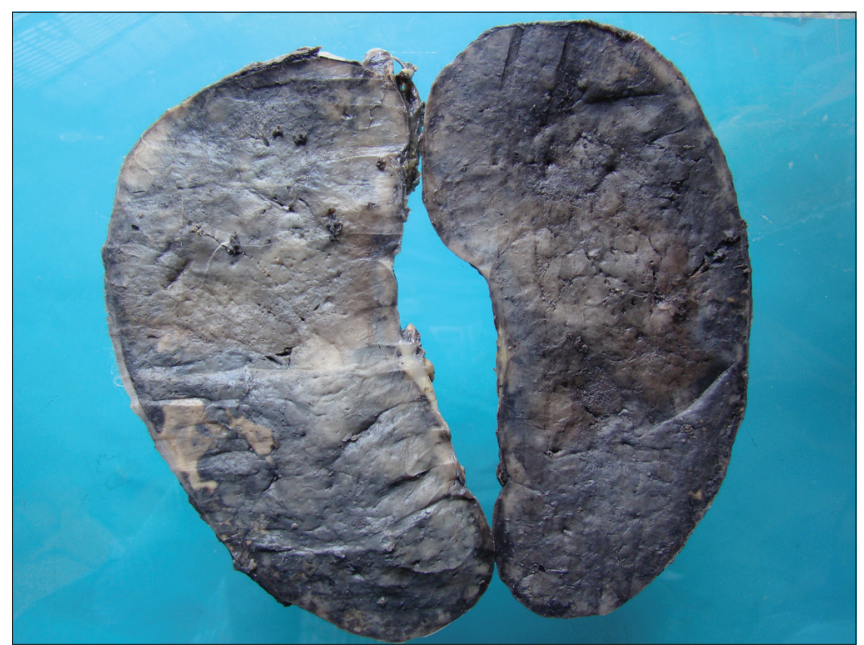

Figure 2: Gross specimen showing the cut surface of the spleen

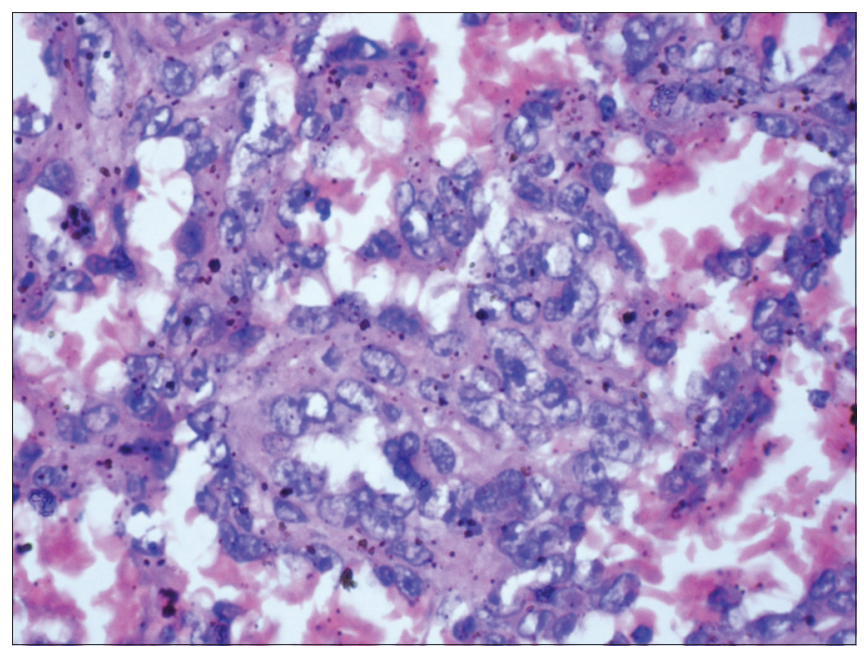

Figure 4: Photomicrograph showing a vascular neoplasm composed of anastomosing vascular channels lined by pleomorphic endothelial cells ( $\mathrm{H}$ and $\mathrm{E}, \times 400)$

\section{DISCUSSION}

Primary angiosarcoma is an extremely rare neoplasm with reported incidence of $0.14-0.23$ cases per million. ${ }^{[2]}$ It may develop at any age, however, the mean age at presentation reported in the literature is 59 years ranging from 14 months to 89 years $^{[2-4]}$ with a slight predominance in men.

Clinical presentation range from asymptomatic disease to splenic rupture and lethal hemorrhage. Splenic rupture occurs in $13 \%-32 \%$ of patients and presents as the most serious manifestation in most of the cases. It is the worst prognostic factor because it puts the patient at an increased risk of peritoneal dissemination. Fever as an associated symptom has been observed in nearly $10 \%$ of the patients with angiosarcoma. ${ }^{[2]}$ Sun et al. investigated splenectomy in 35 patients of pyrexia of unknown origin

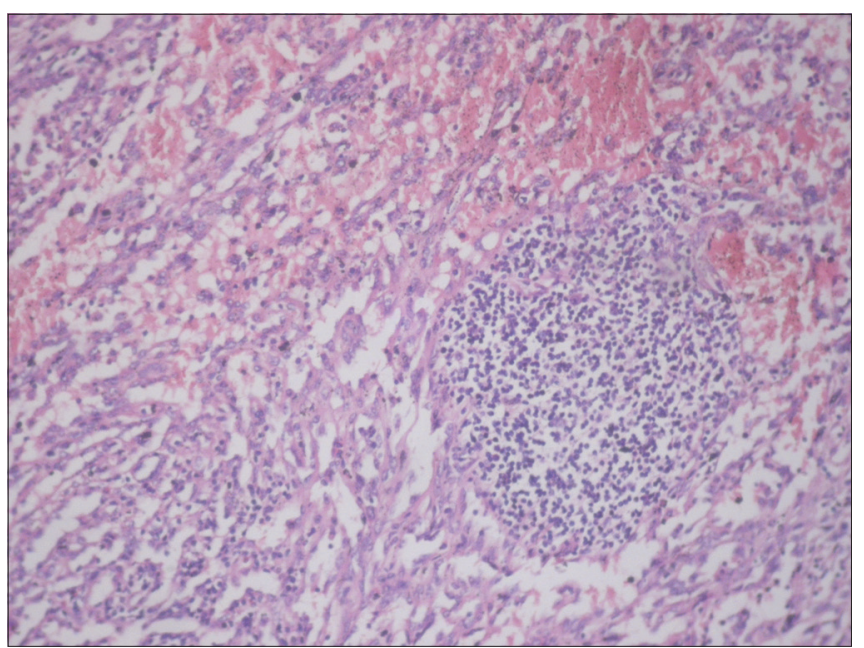

Figure 3: Photomicrograph showing vascular neoplasm composed of anastomosing vascular channels $(\mathrm{H}$ and $\mathrm{E}, \times 100)$

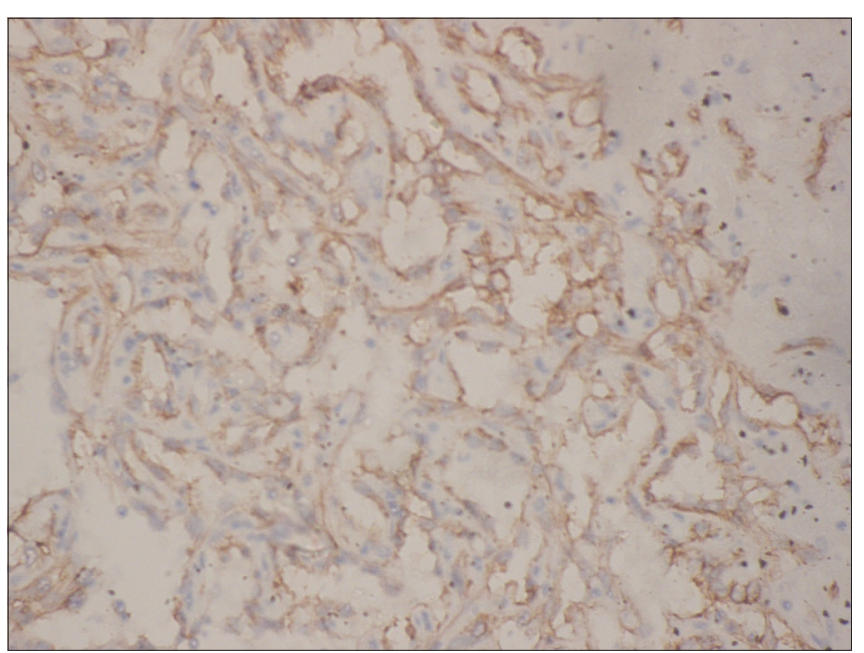

Figure 5: Photomicrograph showing immunohistochemistry with CD31 showing membranous positivity 
and found 1 case $(2.9 \%)$ of splenic angiosarcoma. ${ }^{[5]}$ It was the most common feature in the series of Sordillo et al. (1981), where it was present in almost all of the 4 cases. ${ }^{[6]}$ Hemolytic anemia with angiosarcoma has been previously reported in a patient with vinyl chloride exposure, ${ }^{[7]}$ it was also present in 3 out of 4 cases in the series of Sordillo et al. ${ }^{[6]}$

Radiologically, splenic angiosarcoma presents as splenomegaly; with solitary or multiple heterogeneous mass lesions with increased echogenecity and poor margins. Associated hepatic lesions or retroperitoneal lymph node enlargement may also be seen. ${ }^{[8]}$ Besides these a subcapsular hematoma was also identified on ultrasonography in our case; however, CT scan abdomen showed a characteristic picture consisting of splenomegaly with heterogeneous contrast enhancement and subcapsular hematoma with multiple ill-defined nodules in the splenic parenchyma, suggesting a diagnosis of splenic angiosarcoma with subcapsular rupture of the spleen. Radiologically, splenic angiosarcoma mimic portal hypertension at times, only 1 case of primary hemangiosarcoma associated with documented portal hypertension and functional splenic aplasia has been reported in the literature. ${ }^{[0]}$

Exploratory laparotomy with splenectomy provides tissue diagnosis. Polydrug chemotherapy, including doxorubicin, daunorubicin, and vincristine, has been proposed to offer benefit. ${ }^{[10]}$ Megavoltage radiotherapy is used for symptomatic palliation of bone metastasis. ${ }^{[10]}$

Primary angiosarcoma of spleen is a very aggressive neoplasm with high metastatic rate and poor prognosis with mean survival time 10.3-14.4 months. ${ }^{[10]}$ Concomitant malignancies are found in 5\% of the patients and include carcinoma breast; colorectal carcinoma and non-Hodgkin's lymphoma. ${ }^{[11]}$

\section{CONCLUSIONS}

Splenic angiosarcoma is a rare tumor of the spleen and often mimic splenic trauma and hemorrhage, high degree of suspicion, and a laparotomy with splenectomy often helps in establishing the diagnosis. The role of chemotherapy and radiotherapy has not been established. Presentation as segmental portal hypertension and anemia is rare.

\section{REFERENCES}

1. Manouras A, Giannopoulos $P$, Toufektzian L, Markogiannakis $H$, Lagoudianakis E, Papadima $A$, et al. Splenic rupture as the presenting manifestation of primary splenic angiosarcoma in a teenage women: A case report. J Med Case Reports 2008;2:133.

2. Falk S, Krishnan J, Meis JM. Primary angiosarcoma of the spleen. A clinicopathologic study of 40 cases. Am J Surg Pathol 1993;17:959-70.

3. Valbuena JR, Levenback C, Mansfield P, Liu J. Angiosarcoma of the spleen clinically presenting as metastatic ovarian cancer. A case report and review of literature. Ann Diagn Pathol 2005;9:289-92.

4. Neuhauser TS, Derringer GA, Thompson LD, Fanburg-Smith JC, Miettinen M, Saaristo $A$, et al. Splenic angiosarcoma: A clinicopathologic and immunophenotypic study of 28 cases. Mod Pathol 2000;13:978-87.

5. Sun HY, Zheng M, Liu WL, Zhou JF, Deng JN, Huang M. The clinical application of splenectomy in pyrexia of unknown origin with splenomegaly. Zhonghua Nei Ke Za Zhi 2005;44:89-91.

6. Sordillo EM, Sordillo PP, Hajdu SI. Primary hemangiosarcoma of the spleen: Report of four cases. Med Pediatr Oncol 1981;9: 319-24.

7. Michot F, Bruggisser D, Fehr H, Yurtsever H, Anabitarte M. Microangiopathic hemolytic anemia, erythrophagocytosis and consumptioncoagulopathy in vinyl chloride-induced hemangiosarcoma of the spleen and liver. Schweiz Med Wochenschr 1987;117:990-5.

8. Thompson WM, Levy AD, Aguilera NS, Gorospe L, Abbott RM. Angiosarcoma of the spleen: Imaging characteristics in 12 patients. Radiology 2005;235:106-15.

9. Yücel $A E$, Durak H, Bernay I, Bayraktar $Y$, Bekdik C, Telatar $H$. Functional asplenia and portal hypertension in a patient with primary splenic hemangiosarcoma. Clin Nucl Med 1990;15:324-6.

10. Hai SA, Genato R, Gressel I, Khan P. Primary splenic angiosarcoma: Case report and literature review. J Natl Med Assoc 2000;92:143-6.

11. Kinoshita A, Sakon M, Monden M, Gotoh M, Kobayashi K, Okuda $\mathrm{H}$, et al. Triple synchronous malignant tumours - hepatic leiomyosarcoma, splenic angiosarcoma and sigmoid colon cancer: A case report. Acta Chir Scand 1988;154:477-9.

How to cite this article: Shukla M, Basu S, Shukla VK, Kumar M. Fever, anemia, and splenomegaly: A rare presentation of splenic angiosarcoma. Indian J Med Paediatr Oncol 2011;32:230-2.

Source of Support: Nil, Conflict of Interest: None declared. 